\title{
IMPLEMENTASI KURIKULUM 2013 DALAM PENDIDIKAN INKLUSI DI ROYAL WELLS SCHOOL KOTA BEKASI
}

\author{
YUDHA HADI PURNAMA \\ Pascasarjana PMIPA, Universitas Indraprasta PGRI, Jakarta \\ e-mail : gampangdiingatbanget@gmail.com
}

\begin{abstract}
ABSTRAK
Kurikulum pada kelas inklusi harus dikembangkan dengan mengikuti kebutuhan dan kondisi masing-masing siswa. Kurikulum yang digunakan adalah kurikulum modifikasi dan juga sebagai perwujudan sekolah ramah anak. Penelitian ini bertujuan untuk melihat implementasi kurikulum pada sekolah penyelenggara pendidikan inklusif terkait aspek perencanaan, pelaksanaan dan evaluasi pembelajaran serta faktor pendukung dan penghambat penyelenggaraan pendidikan inklusif. Penelitian ini dilakukan dengan menggunakan metode deskriptif, dan pendekatan kualitatif yang dilakukan di Sekolah Royal Wells School di Kota Bekasi. Penggalian data menggunakan teknik wawancara, observasi dan studi dokumen. Hasil penelitian menunjukkan bahwa sekolah wajib melakukan penyelarasan kurikulum dengan cara melakukan asesmen-mengembangkan program pembelajaran individual-diskusi dengan orang tua, guru kelas, dan kepala sekolah. Pada pelaksanaan pembelajaran di kelas yang dilakukan oleh guru kelas, namun bagi Siswa Inklusiyang menerima materi saat pembelajaran dibimbing oleh guru pendamping khusus. Dan untuk evaluasi pembelajaran dilakukan dengan penyesuaian tingkat kesulitan pertanyaan, jumlah soal, dan cara menjawab pertanyaan yang disesuaikan dengan kemampuan peserta didik. Untuk mencapai tujuan tersebut dukungan pimpinan, rekan sejawat dan orang tua murid sangat dibutuhkan, sedangkan beberapa faktor yang menghambat adalah masih terdapat kebijakan di tingkat sekolah yang belum komprehensif, masyarakat yang belum paham, perencanaan penyelarasan kurikulum yang belum di supervisi, sarana dan prasarana yang kurang memadai. Rekomendasi dari hasil penelitian ini adalah sekolah tersebut harus melakukan sosialisasi kebijakan kepada calon orangtua siswa baik regular maupun inklusif, memperhatikan kompetensi sumber daya tenaga pengajar, serta melakukan supervisi implementasi pendidikan inklusif di sekolah.
\end{abstract}

Kata Kunci: Implementasi kurikulum, Pendidikan inklusif

\section{ABSTRACT}

The curriculum in inclusive classes must be developed by following the needs and conditions of each student. The curriculum used is a modified curriculum as well as the embodiment of a child-friendly school. This study aims to look at the implementation of the curriculum in inclusive education providers related to aspects of planning, implementation and evaluation of learning as well as the supporting and inhibiting factors for the implementation of inclusive education. This research was conducted using a descriptive method, and a qualitative approach was carried out at the Royal Wells School in Bekasi City. Data mining used interview, observation and document study techniques. The results of the study indicate that schools are required to carry out curriculum alignment by conducting assessments-developing individual learning programs-discussions with parents, class teachers, and school principals. In the implementation of classroom learning carried out by class teachers, but for Inclusive Students who receive material during learning are guided by special assistant teachers. And for the evaluation of learning, it is done by adjusting the level of difficulty of the questions, the number of questions, and how to answer questions that are adjusted to the abilities of students. To achieve this goal, support from leaders, peers and parents of students is very much needed, while several inhibiting factors are that there are still policies at the school level that are not yet comprehensive, people who do not understand, planning for curriculum alignment that has not been supervised, inadequate facilities and infrastructure. adequate. The recommendation from the results of this study is that the school must disseminate policies to prospective parents of 
students both regularly and inclusively, pay attention to the competence of teaching staff resources, and supervise the implementation of inclusive education in schools.

Keywords: curriculum implementation, inclusive education

\section{PENDAHULUAN}

Sejatinya pendidikan adalah bagi seluruh masyarakat tidak terkecuali dan tidak membedabedakan setiap individunya, hak untuk memperoleh pendidikan tertuang pada UUD 1945 Pasal 28c Ayat (1) dan juga disebutkan dalam UU No 20 Tahun 2003 Pasal 5 tentang Sistem Pendidikan Nasional, yang menyatakan bahwa pemerintah menjamin pendidikan bagi seluruh peserta didik tanpa membedakan ras, agama, suku, gender, keterbatasan fisik dan mental. Kebijakan yang ada saat ini pun menekankan pendidikan inklusif sebagai konsep reformasi dalam pendidikan karena diakui secara internasional bahwa pendekatan pendidikan inklusif merupakan pendidikan yang memanusiakan manusia (Kuppies \& Peters, 2014).

Pendidikan Inklusif menurut Smith (2015) adalah penerimaan anak-anak yang memiliki hambatan ke dalam kurikulum, lingkungan, interaksi sosial dan konsep (visi-misi) sekolah. Pendidikan inklusif semakin ditekankan secara internasional dengan dilakukankan kesepakatan terhadap pernyataan Deklarasi Salamanca (UNESCO) tahun 1994 di mana Indonesia menjadi salah satu peserta yang mengikuti kongres tersebut. Isi deklarasi tersebut dirangkum oleh Skjorten (2001) menyebutkan bahwa hak semua anak, termasuk mereka yang berkebutuhan temporer dan permanen untuk memperoleh penyesuaian pendidikan agar dapat mengikuti sekolah,

Pendidikan inklusif dipandang baik karena selain memanusiakan manusia pendidikan inklusif yang diterapkan di Indonesia diharapkan mampu memeratakan pendidikan bagi siswa berkebutuhan khusus di mana ABK tidak harus ke SLB untuk mendapatkan layanan pendidikan dikarenakan jumlah SLB tidak sebanyak sekolah reguler, sehingga siswa berkebutuhan khusus dapat mencari sekolah terdekat dan mudah diakses oleh ABK, maka pemerataan pendidikan dan layanan pendidikan bagi seluruh anak Indonesia dapat terpenuhi.

Dampak positif dari diselenggarakannya pendidikan inklusif yaitu mampu membuat siswa berkebutuhan khusus lebih merasa di terima di masyarakat dan dihargai, tidak hanya itu, peserta didik reguler pun saat memiliki teman atau lingkungan sosial yang terdapat $A B K$, mereka belajar bagaimana bersikap toleransi dan menghargai serta menolong teman yang memiliki keterbatasan (McMurray \& Thompson, 2016). Banyak dampak positif dari diselenggarakannya pendidikan inklusif inilah yang menjadikan sistem pendidikan inklusif baik untuk dilaksanakan (Bakken \& Obiakor, 2016). Giangreco (1997) juga menyebutkan dampak yang ditimbulkan pada penyelenggaraan pendidikan inklusif

Kurikulum sebagai salah satu komponen utama dalam pendidikan menjadi salah satu aspek yang masih memiliki kendala dalam implementasinya, terutama pada implementasi kurikulum pada sekolah penyelenggara pendidian inklusif, dimana memiliki ciri khas tersendiri bagi kelas inklusif. Kurikulum sebagai cetak biru pendidikan, menjadikan kurikulum sebagai suatu pedoman yang berisikan arah dan tujuan dari pendidikan, dapat diasumsikan sebagai pendidikan secara luas atau nasional, maupun pendidikan anak secara individual dan berisikan pengalaman pengalaman belajar yang telah direncanakan supaya dimiliki oleh peserta didik. Pengertian kurikulum di Indonesia tertuang dalam Undang Undang No. 20 Pasal 1 Ayat 19 Tahun 2003 Tentang Sistem Pendidikan Nasional yang menyatakan bahwa "Kurikulum merupakan seperangkat rencana dan pengaturan mengenai tujuan, isi, dan bahan pelajaran, serta cara yang digunakan sebagai pedoman penyelenggaraan kegiatan pembelajaran untuk mencapai tujuan pendidikan tertentu". Melalui definisi tersebut kurikulum diartikan sebagai perangkat rencana berisikan komponen kurikulum yang dituangkan ke dalam dokumen pembelajaran dengan disusun secara sistematis dan sistemik untuk memberikan pengalaman belajar agar tercapainya tujuan pendidikan, dan dokumen tertulis tersebut digunakan sebagai acuan dalam implementasi pembelajaran sampai pada pelaksanaan di kelas. 
Kurikulum yang digunakan pada Sekolah Royal Wells School adalah kurikulum 2013 yang juga digunakan pada kelas inklusif. Pada dasarnya menggunakan kurikulum pada kurikulum sekolah umum, namun bagi Siswa InklusiSD, kurikulum yang ada perlu di sesuaikan atau dimodifikasi mengikuti kemampuan peserta didik berkebutuhan khusus. Kelas inklusif memiliki ciri khas keberagaman yang sangat dominan, dengan demikian prinsip fleksibilitas kurikulum akan terlihat. Assesment pada siswa inklusif menunjukkan bahwa kebanyakan dari mereka dapat mengikuti pembelajaran reguler namun tidak dapat bersosialisasi dengan baik mengingat keterbatasan mereka. Sekolah Royal Wells School harus mempunyai suatu kurikulum khusus yang adaptif dan fleksibel untuk dapat disesuaikan dengan kebutuhan siswa inklusif maupun regular. Berdasarkan pada data dan penjelasan di atas, maka pada penelitian ini secara umum rumusan masalah adalah untuk mengetahui bagaimakah implementasi kurikulum 2013 pada sekolah penyelenggara pendidikan inklusif di Sekolah Royal Wells School

\section{METODE PENELITIAN}

Penelitian ini dilaksanakan dengan menggunakan pendekatan penelitian kualitatif. Teknik pengumpulan data dilakukan dengan wawancara, observasi, dan dokumentasi. Data dianalisis melalui reduksi data, model data, dan penarikan kesimpulan atau verifikasi. Teknik keabsahan data yang digunakan yaitu triangulasi. Subjek dalam penelitian ini berkaitan dengan penyelenggaraan kurikulum bagi peserta didik berkebutuhan khusus, yang terdiri dari:

Tabel 1. Lokasi dan subjek penelitian

\begin{tabular}{|c|c|c|}
\hline INITIAL & SUBJEK & LOKASI \\
\hline S.S & Kepala Sekolah Dasar & \\
\hline D.Z & $\begin{array}{c}\text { Koordinator Kelas } \\
\text { Inklusi }\end{array}$ & $\begin{array}{c}\text { ROYAL WELLS } \\
\text { SCHOOL }\end{array}$ \\
\hline R.E & Wali Kelas & \\
\hline S.A & $\begin{array}{c}\text { Pendamping Kelas } \\
\text { Inklusi }\end{array}$ & \\
\hline
\end{tabular}

Informan dalam penelitian ini merupakan pihak yang berhubungan langsung dengan implementasi kurikulum 2013 di SD Royal Wells School yang nama terangnya diinisialkan untuk menjaga privasi informan dalam publikasi penelitian.

Dalam penelitian ini, teknik pengumpulan data yang digunakan adalah:

a. Wawancara

Dalam penelitian ini, wawancara akan dilakukan kepada beberapa pihak, antara lain wakil kepala bagian kurikulum, guru pendamping khusus, dan guru kelas/wali kelas.

b. Observasi

Penelitian ini dalam observasi meliputi, observasi dalam proses pembelajaran di kelas. Dokumentasi Pada penelitian ini dokumentasi dilakukan sebagai data penunjang untuk memperkuat hasil penelitian. Dimana dokumen tersebut bisa berbentuk tulisan.

\section{HASIL DAN PEMBAHASAN}

Hasil penelitian berisi deskripsi hasil analisis data penelitian yang sudah terorganisasi dengan baik. Data penelitian disajikan secara informatif, komunikatif, dan relevan dengan masalah dan tujuan penelitian. Dalam bab ini, hasil penelitian berupa deskripsi analisis yang disajikan dalam uraian bersifat kualitatif yaitu data yang digambarkan dengan kata-kata atau kalimat. Adapun hasil penelitian ini merupakan paparan data hasil penelitian yang berhasil digali melalui wawancara, observasi, serta dokumentasi terhadap peristiwa dan hasil kajian terhadap beberapa dokumen yang dipilih oleh peneliti. Menurut D.Z sebagai koordinator inklusi mengatakan bahwa pendidikan inklusi merupakan model penyelenggaraan pendidikan bagi 
anak berkebutuhan khusus. Menurut Herawati dalam artikelnya model yang lain diantaranya meliputi:

a) Sekolah regresi meliputi sekolah yang memisahkan anak berkerbutuhan khusus dari sistem persekolahan reguler. Di Indonesia bentuk sekolah segresi ini berupa satuan pendidikan khusus atau Sekolah Luar Biasa sesuai dengan jenis kelainan peserta didik. Seperti SLB/A untuk anak Tuna netra, SLB/B untuk anak tuna rungu, SLB/E untuk anak tuna laras dan lain-lain. Sistem pendidikan yang digunakan terpisah sama sekali dari sistem pendidikan di sekolah reguler, baik kurikulum, tenaga pendidik dan kependidikan, sarana prasarana, sampai pada sistem pembelajaran dan evaluasinya.

b) Sekolah terpadu adalah sekolah yang memberikan kesempatan kepada Siswa Inklusiuntuk mengikuti pendidikan di sekolah reguler tanpa adanya perlakuan khusus yang disesuaikan dengan kebutuhan individual anak. Sekolah tetap menggunakan kurikulum, sarana prasarana, tenaga pendidik dan kependidikan, serta sistem pembelajaran reguler untuk semua peserta didik. Jika ada peserta didik tertentu mengalami kesulitan dalam mengikuti pendidikan, maka konsekuensinya peserta didik itu sendiri yang harus menyesuaikan dengan sistem yang dituntut di sekolah reguler. Dengan kata lain pendidikan terpadu menuntut anak yang harus menyesuaikan dengan sistem yang dipersyaratkan sekolah reguler.

c) Sekolah inklusif merupakan perkembangan baru dari pendidikan terpadu. Pada sekolah inklusif setiap anak sesuai dengan kebutuhan khususnya, semua diusahakan dapat dilayani secara optimal dengan melakukan berbagai modifikasi dan/atau penyesuaian, mulai dari kurikulum, sarana prasarana, tenaga pendidik dan kependidikan, sistem pembelajaran sampai pada sistem penilaiannya. Dengan kata lain pendidikan inklusif mensyaratkan pihak sekolah yang harus menyesuaikan dengan tuntutan kebutuhan individu peserta didik, bukan peserta didik yang menyesuaikan dengan sistem persekolahan.

Pernyataan tersebut jelas berbeda antara sekolah regresi, terpadu dan sekolah inklusi. Dalam hal ini pendidikan inklusi memberikan kesempatan dan memanusiakan-manusia tanpa melihat latar belakang, siswa diberikan kesempatan untuk berinteraksi dengan bebas dan mengikuti pelajaran dan mendapatkan teman seperti siswa-siswa yang lainnya. Herawati juga menjelaskan bahwa dalam manajerial sekolah inklusif bahwasannya sekolah reguler harus siap mengelola kelas yang heterogen dengan menerapkan kurikulum dan pembelajaran yang bersifat individual. Menurut Aslan (2017, hlm. 1) mengatakan bahwa anak berkebutuhan khusus dan anak normal, tingkat kurikulumnya sama saja, tapi disisi lain perbedaanya pasti ada, yakni pada evaluasinya.

Sekolah Royal Wells School yang mana telah dilaksanakan observasi bahwa terlihat memang adanya kelas heterogen. Dimulai dari kelas L.1 sampai pada L.6 atau (Level 1-level 6), semua kelas terisi dengan siswa-siswi berkebutuhan dan siswa-siswi yang reguler (normal). Menurut Tiara (2019, hlm. 24) Sikap sosial merupakan ekspresi atau tindakan seseorang dalam menyikapi sesuatu dalam kehidupan sosial. Kelas merupakan tempat dimana siswa berinteraksi dengan lingkungan sekitarnya. Di dalam kelas yang heterogen tersebut agar tercipta budaya dan pengalaman belajar oleh siswa tentang bagaimana sikap menghormati, mengasihi dan menyayangi sesama teman baik yang berkebutuhan ataupun siswa dalam kategori normal. Menurut paparan F.m selaku koordinator inklusi mengatakan bahwa, adanya hubungan yang baik antara orang tua, educator dan guru pendamping untuk bekerjasama agar terciptanya rasa dukungan yang akan berpengaruh pada perkembangan psikologis anak. Hasil wawancara yang dilakukan kepada S.S selaku Kepala Sekolah mengatakan bahwa dalam kurikulum 2013 sangat berdampak positif pada siswa reguler maupun berkebutuhan. Sistem pendidikan di Indonesia telah mengalami beberapa kali perbaikan kurikulum. Hal ini tercermin dengan adanya perubahan kurikulum, mulai dari kurikulum 1947, 1952, 1964, 1968, 1975, 1984, 1994, 2004, 2006, dan 2013. Perbaikan kurikulum merupakan bagian penting dalam pengembangan kurikulum yang bertujuan untuk meningkatkan kualitas pendidikan sesuai dengan tujuan 
pendidikan nasional. Menurut Fadlillah (2014, hlm. 31). Kurikulm 2013 sangat detail dalam kompetensi inti, dan sangat bagus dalam pengembangan karakter siswa. Menurut Mahmuddah (2017, hlm. 261)

Pengembangan karakter dilakukan dengan menanamkan nilai-nilai etika dasar (core ethical values) sebagai basis bagi karakter yang baik. Tujuannya adalah agar peserta didik mempunyai karakter yang baik. Indikator karakter yang baik terdiri dari pemahaman dan kepedulian pada nilai-nilai etika dasar serta tindakan atas dasar inti nilai etika atau etika yang murni. Selain itu tujuan lain dalam karakter siswa dalam kurikulum 2013 sangat berpengaruh pada siswa berkebutuhan khusus. Peran keluarga, masyarakat dalam membangun karakter mendapatkan dampak yang signifikan dalam memelihara dan mengasuh siswa berkebutuhan. Kesiapan tersebut merupakan kunci pengobatan untuk menyediakan lingkungan yang ramah.

Dalam K.I 2 yang merupakan hubungan sosial, menerapkan karakter sopan santun pada siswa baik reguler maupun non reguler. Namun dalam kurikulum 2013 guru kesulitan dalam K.I 3 dan K.4 yang merupakan aspek ilmu pengetahuan dan aspek keterampilan. Pemaparan S.S tersebut mengatakan bahwa K.I 1 dan K.2 ada form tersendiri, form tersebut digunakan sebagai catatan harian dan akan dilaporkan pada akhir semester. Berbeda dengan K.I 3 dan K.4 guru perlu memperhatikan secara detail sebagai evaluasi proses ketika kegiatan belajar mengajar berlangsung. Kelemahannya pada form tersebut guru-guru mengisi pada saat waktu luang, dan bahkan form tersebut ada yang tidak diisi sama sekali.

Hasil wawancara dengan D.Z bahwasannya untuk siswa berkebutuhan ada grade tersendiri. Untuk menentukan itu dari pihak sekolah dan bekerjasama dengan psikolog serta orang tua siswa diberikan assessmen untuk mengetahui apakah siswa berkebutuhan butuh untuk pendampingan dari guru pendamping khsus, ataukah siswa berkebutuhan memang sudah mandiri untuk mengikuti pembelajaran di kelas. Berdasarkan studi dokumentasi juga didapatkan bentuk RPP dalam kurikulum 2013 belum adanya perbedaan yang signifikan antara siswa berkebutuhan dan siswa reguler. Di Royal Wells School menurut D.Z sebagai koordinator inklusi juga mengatakan bahwasannya silabus ataupun RPP untuk siswa berkebutuhan seharusnya memiliki perbedaan pada indicator, learning goals dan learning methods yang mana disesuaikan pada kebutuhan siswa yang berkebutuhan. Namun karena kesibukan guru untuk mengurusi hal yang lainnya, tidak semua guru merubah dan membedakan RPP siswa reguler maupun siswa berkebutuhan. Sebab hal lain, terkait metode belajar diserahkan kepada guru pendamping khusus. Selain pada tugas guru pendamping khusus untuk ikut membantu pada proses perencanaan pembelajaran. Selanjutnya pada tahap evaluasi pada siswa berkebutuhan khusus dan akan dijadikan laporan akhir semester, guru pendamping khusus memberikan laporan tentang perkembangan siswa yang diampu atau yang diberikan pendampingan khusus. Namun dengan kendala situasi yang ada, guru mata pelajaran ataupun wali kelas memiliki kesibukan maka terkadang guru membuat RPP disamakan indikator keberhasilan siswa reguler dan siswa berkebutuhan.

Menurut Mumpuniarti (2007 : 77) idealnya semua anak berkebutuhan khusus dilayani program pembelajaran individual (PPI). Berdasarkan hasil wawancara dengan S.A sebagai guru pendamping khusus mengatakan bahwa, guru pendamping khusus dalam proses pembelajaran dan pentransferan suatu pelajaran untuk siswa berkebutuhan mengalami kesulitan dalam mata pelajaran tematik, yang mana mata pelajaran tematik merupakan satu kesatuan dari mata pelajaran IPA, IPS, PPKN, Bahasa Indonesia dan Seni Budaya. Dalam kurikulum 2013 menekankan pada siswa untuk dapat mandiri dan menerima pembelajaran dengan inovatif, namun untuk guru pendamping sendiri hanya dapat menjelaskan secara terbatas untuk siswa berkebutuhan. Guru pendamping khusus mengatakan memang dalam metode pembelajaran sangat berbeda untuk siswa berkebutuhan itu sendiri. Misal siswa yang memiliki gangguan pemusatan perhatian akan berbeda metode atau cara penyempaian yang diberikan kepada siswa yang memiliki diseleksia. Hal terpenting adalah kurikulum apapun yang digunakan perlunya guru yang mengajar anak berkebutuhan harus memiliki kejelian dan kepekaan terhadap anak. 


\section{KESIMPULAN}

Dari penjelasan diatas dapat disimpulkan bahwa:

1. Implementasi kurikulum adaptif bagi Siswa Inklusi di Sekolah Royal Wells School.

Pada proses persiapan implementasi kurikulum 2013, kepala sekolah telah melakukan persiapan sumber daya manusia serta sarana prasarana. Pada persiapan sumber daya manusia, kepala sekolah menugaskan guru-guru untuk mengikuti workshop dan pelatihan tentang implementasi kurikulum 2013. Sedangkan pada persiapan sarana prasaran, kepala sekolah selalu berusaha untuk meningkatkan sarana prasarana yang telah ada dalam mendukung proses pembelajaran dengan implementasi kurikulum 2013. Pada kegiatan perencanaan proses pembelajaran guru menyiapkan perangkat pebelajaran dengan dilakukan nya penyesuaian bagi siswa inklusi. Penyesuaian tersebut meliputi penyesuai proses dan penyesuaian evaluasi. Pada kegiatan pelaksanaan proses pembelajaran, penyampaian materi disesuaikan juga dengan kebutuhan dan kemampuan siswa. Pada kegiatan evaluasi proses pembelajaran terdapat perbedaan standar penilaian bagi peserta didik regular dengan peserta inklusi. Terdapat pula program remidial bagi peserta didik yang memiliki nilai di bawah KKM yang telah ditetapkan.

2. Kendala-kendala yang dihadapi dalam implementasi kurikulum 2013 bagi Siswa Inklusidi Sekolah Royal Wells School.

Kendala yang ada meliputi cara penyampaian materi atau metode pembelajaran bagi siswa inklusi. Selain itu kendala lainya mengenai proses penilaian. Dalam proses pembelajaran, guru regular mengalami cukup kesulitan dalam hal penyampaian materi serta dalam hal pemilihan metode yang tepat dan sesuai dengan kebutuhan dan kemampuan siswa inklusi.

3. Solusi untuk mengatasi kendala-kendala yang dialami dalam implementasi kurikulum 2013 bagi Siswa Inklusi di Sekolah Royal Wells School.

Kepala sekolah memberikan workshop serta pemahaman kepada guru regular mengenai Siswa Inklusi dan metode pembelajaran yang sesuai. Selain itu guru juga perlu mendapatkan pelatihan lanjutan mengenai kurikulum 2013 sampai pada proses penilaian. Dibutuhkan kerjasama dalam penyusunan program pembelajaran pada mata pelajaran olahraga serta pada pelajaran TIK. Selain itu peran serta peserta didik regular yang ada dalam kelas, juga sangat berpengaruh, yaitu dengan saling mengingatkan dan membantu Siswa Inklusi dalam proses pembelajaran agar lebih menyenangkan.

\section{DAFTAR PUSTAKA}

Bagaskorowati, Riana. (2010). Anak Berisiko. Identifikasi, Asesmen, dan Intervensi Dini. Bogor; Ghalia Indonesia

Barnawi dan Arifin, M. 2014. Manajemen Sarana dan Prasarana Sekolah. Jogjakarta; Ar-Ruzz Media

Chris Forlin, Dianne Chambers, Tim Loreman, Joanne Deppeler, and Umesh Sharma. (2013). Inclusive Education for Students with Disability, A Review of The Best Evidence in Relation to Theory and Pracitce. Australia: ARACY

Daryanto dan Sudjendro, Herry. (2014). Siap Menyongsong Kurikulum 2013. Yogyakarta; Gava Media

Emzir. (2011). Metodologi Penelitian Kualitatif Analisis Data. Jakarta; Rajawali Pers

Ghony, Djunaidi dan Almanshur, Fauzan. (2014). Metodologi Penelitian Kualitatif. Jogjakarta; Ar-Ruzz Media

Grafura, Lubis dan Wijayanti, Ari. 2014. Strategi Implementasi Pendidikan Sesuai Kurikulum 2013 di Jenjang SMK. Jakarta; Prestasi Pustaka

Ilahi, Mohammad Takdir. (2013). Pendidikan Inklusif: Konsep dan Aplikasi. Jogjakarta; ArRuzz Media

Kementrian Pendidikan dan Kebudayaan Republik Indonesia. (2014). Pedoman Pelaksanaan Kurikulum bagi Peserta Didik Berkebutuhan Khusus di Sekolah Reguler. Jakarta; Kementrian Pendidikan dan Kebudayaan Republik Indonesia 
Kurniasih, Imas dan Sani Berlin. (2014). Sukses Mengimplementasikan Kurikulum 2013, Memahami Berbagai Aspek Dalam Kurikulum 2013. Jakarta; Kata Pena

Ulfatin, Nurul. (2015). Metode Penelitan Kualitatif di Bidang Pendidikan: Teori dan Aplikasinya. Malang; Media Nusa Creative

Walentiningsih dan Ida ayu, Ulan. (2011). Pakem Sekolah Inklusi. Malang; Bayumedia Publishing

Yani, Ahmad. (2014). Mindset Kurikulum 2013. Bandung; Alfabeta 